\title{
RESEARCH
}

Open Access

\section{Partnering and parenting transitions in Australian men and women: associations with changes in weight, domain-specific physical activity and sedentary behaviours}

\author{
Jing $\operatorname{Tian}^{1^{*}}$ (D, Kylie J. Smith ${ }^{1}$, Verity Cleland ${ }^{1}$, Seana Gall ${ }^{1}$, Terence Dwyer ${ }^{1,2}$ and Alison J. Venn ${ }^{1}$
}

\begin{abstract}
Background: Partnering and parenting are important life-stage transitions often accompanied by changes in social networks, roles and responsibilities. There have been no longitudinal studies examining associations of partnering and parenting with changes in domain-specific physical activity (PA) and sedentary behaviours, and our understanding of whether these transitions are associated with weight change is limited.

Methods: Two thousand one hundred and twenty-four Australian adults from a national cohort (mean age 31.7 (2.7) years, 47.5\% male) completed questionnaires at baseline (2004-06) and follow-up (2009-11), reporting marital and parental status. Weight $(\mathrm{kg})$ was measured at baseline and self-reported at follow-up. PA and sedentary behaviours (sitting and television (TV) viewing) were self-reported in a subset $(n=1221)$. Linear regression estimated the longitudinal associations of parenting and partnering transitions with PA, sedentary behaviours and weight at follow-up, adjusted for baseline value of the respective outcome variable, age, education, follow-up duration and other life-stage transition.

Results: During the 5-year follow-up, 17.3\% men and 12.9\% women partnered, and 27.3\% men and 19.1\% women had their first child. Compared to staying not partnered, partnering was associated with an increase in total PA (177.5 mins/week, 95\% Confidence Interval (Cl) 18.0 to 337.0$)$ among men and a greater weight gain $(2.2 \mathrm{~kg}, 95 \% \mathrm{Cl}$ 0.6 to 3.7) among women. Compared to remaining child-free, having a first child was associated with greater reductions in total PA $(-123.9 \mathrm{mins} /$ week, $95 \% \mathrm{Cl}-248.8$ to 1.1$)$ and TV viewing time $(-27.0 \mathrm{mins} /$ day, $95 \% \mathrm{Cl}-$ 50.6 to -3.3$)$ among men. Women who had their first child had greater weight gain $(1.4 \mathrm{~kg}, 95 \% \mathrm{Cl} 0.1$ to 2.7$)$ but spent less time sitting $(-103.8$ mins/day, $95 \% \mathrm{Cl}-135.5$ to -72.1$)$ than those remaining child-free. For women, having additional children was associated with less sitting time $(-39.4$ mins/week, $95 \% \mathrm{Cl}-66.0$ to -12.8$)$ than having the same number of children.

(Continued on next page)
\end{abstract}

\footnotetext{
* Correspondence: J.Tian@utas.edu.au

'Menzies Institute for Medical Research, University of Tasmania, 17 Liverpool Street, Hobart, Tasmania 7000, Australia

Full list of author information is available at the end of the article
}

C C The Author(s). 2020 Open Access This article is licensed under a Creative Commons Attribution 4.0 International License, which permits use, sharing, adaptation, distribution and reproduction in any medium or format, as long as you give appropriate credit to the original author(s) and the source, provide a link to the Creative Commons licence, and indicate if changes were made. The images or other third party material in this article are included in the article's Creative Commons licence, unless indicated otherwise in a credit line to the material. If material is not included in the article's Creative Commons licence and your intended use is not permitted by statutory regulation or exceeds the permitted use, you will need to obtain permission directly from the copyright holder. To view a copy of this licence, visit http://creativecommons.org/licenses/by/4.0/ The Creative Commons Public Domain Dedication waiver (http://creativecommons.org/publicdomain/zero/1.0/) applies to the data made available in this article, unless otherwise stated in a credit line to the data. 
(Continued from previous page)

Conclusions: Partnering was associated with an increase in men's total PA and women's weight. Transitions into parenthood with a first child or additional children were associated with potentially health-impairing changes in weight and PA, but health-promoting changes in sedentary behaviours. Future PA promotion strategies should pay attention to men who had their first child to mitigate declining total PA.

Keywords: Weight, Physical activity, Sedentary behaviour, Marriage, Parent, Young adult

\section{Background}

Becoming partnered and having children are two important life-stage transitions that typically occur in young adulthood. They are accompanied by major changes in social networks and roles, responsibilities and expectations, which may be associated with changes in lifestyle behaviours, such as physical activity (PA) and sedentary behaviour. Over recent decades, transitions to partnership and parenthood have been occurring at later ages. Data from the Australian census in 2016 showed that the median age at first marriage was 30.3 years for males and 28.7 years for females [1], rising by 4.0 and 4.5 years since 1989 respectively [2]. The average age of first-time mothers also increased, from 26.2 years in 1993 [3] to 29.2 in 2017 [4].

Previous studies, with varying follow-up durations, generally show that partnering is associated with weight gain, while divorce/separation/widowhood is associated with weight loss $[5,6]$. However, the findings differed by sex. A 10-year United States (US) study of 9043 men and women found that unmarried women who became married gained more weight than women who remained married at both baseline and follow-up, and men who stayed divorced/widowed and men who became widowed lost more weight than men who remained married at both times [6]. In contrast, one 20-year follow-up of 3347 US men and women reported the association of partnering transitions with weight change was not contingent on sex [5].

There is a large amount of evidence that transition into parenthood is associated with weight gain among women and the magnitude of weight gain is positively related to parity [7]. For example, a cross-sectional US study of 4523 middle-aged couples reported a $7 \%$ increase in obesity risk for each additional child among women [8]. Although the social and biological features of parenthood differ for women and men [9], very few longitudinal studies have quantified weight changes following parenting transitions among men. Using 15-year longitudinal data, one study found that becoming a father was associated with accelerated weight gain [10]. A similar association was reported in a 20 -year longitudinal study of young men [11]. However, these two studies have limitations: one included a wide age range of participants (24-96 years) [10] and both failed to control for important confounders [10, 11], such as the aforementioned partnering transitions.

Associations between partnering transitions and change in PA have been reported by several prospective studies with conflicting findings. Some reported that people who married or started to live as married tended to decrease PA relative to those remaining not partnered [12-16], while others found increased [17] or no significant difference [18-21] in PA. Direct comparison of the results in these studies is difficult because they used different PA measurements varying from one question on leisure and work PA [17], two or three questions on moderate and vigorous leisure time PA in the past week [12-14], leisure time PA in the past year $[16,18]$ and total moderate and vigorous PA from three questions [21]. In addition, the socio-demographics of participants varied widely across studies. Some of them examined participants aged in their twenties [12-14, 18], while others examined a far wider age range of 18-83 [22] and 25-75 years [17] and mid-aged to elderly [16, 20]. Further, some of them included women only [12-14, 20], one included men only [16] while others included both $[17-19,22]$. These characteristics are important as the impacts of partnering transitions on PA were suggested to differ by age and sex [15]. The association between becoming partnered and changing PA became weaker with increasing age and shifted from negative to positive in men [15]. The effect size decreased with increasing age in women as well but stayed negative with older age [15].

Having children has been shown to have negative associations with PA in young women [12-14]. For example, a 3-year follow-up of Australian women aged 22-27 years found that women having their first child during follow-up were $45 \%$ more likely to decrease PA [12]. Only one study has explored the associations between parenting transitions and changing PA in men [18]. This study by Hull et al. [18] followed 638 young adults aged in their mid-twenties (48\% male) for 2 years and found different patterns between parenting transitions and changing leisure time PA for men and women. Having a first child was significantly associated with decreased leisure time PA in both men and women compared with remaining child-free, while having additional children was associated with decreased leisure time PA among 
women but not men compared with having the same number of children [18]. This study also had limitations including small sample, poor generalisability and inadequate control of confounders (e.g. did not adjust for parenting transitions in partnering transition analyses).

Total PA is constructed from different domains relating to occupation, transport, domestic and leisure time PA. The intensity, duration and frequency of each domain are used to estimate total PA. Previous prospective studies have often focused on a limited number of domains, mainly leisure time PA $[12-14,16,18]$. It remains unclear how partnering and parenting transitions associate with other domains and total PA. Data of this kind are important as they will help establish whether interventions that target specific PA domains may be required. Further, no study has explored the associations of partnering and parenting transition with changing sedentary behaviours.

Using data from a large population-based national cohort in Australia, this study aimed to examine 1) whether partnering and parenting transitions were associated with changes in weight, domain-specific PA, total PA and sedentary behaviours over a 5-year period, and 2) whether the associations differed by sex. We hypothesised that 1 ) participants who became partnered or had children during the 5-year follow-up would gain weight and have healthier PA and sedentary behaviours than those who stayed not partnered or child-free and 2) these associations differ between men and women in effect size.

\section{Methods}

\section{Study design}

A prospective cohort study.

\section{Participants}

Participants were from the Childhood Determinants of Adult Health (CDAH) study [23], a follow-up of 8498 participants from the 1985 Australian Schools Health and Fitness Survey (ASHFS), which comprised a nationally representative sample of Australian school children aged 7-15 years. During 2002-4, 6840 participants were traced and 5170 agreed to participate in the CDAH study. The first follow-up was conducted in 2004-6 (CDAH-1, baseline in this study) where 3975 participants aged 26-36 years completed questionnaires and 2410 attended one of 34 study clinics held around Australia for physical measurements. In 2009-11, the second follow-up (CDAH-2, follow-up in this study) collected data from 2820 participants aged 31-41 years via telephone, mail or online survey.

\section{Marital status and partnering transitions}

At baseline and follow-up, participants were asked to report their current marital status (single, married/living as married, and separated/divorced/widowed). This information was used to create a four-category variable of partnering transitions: "stayed not partnered" (single or separated/divorced/widowed at both baseline and follow-up), "became partnered" (single or separated/divorced/widowed at baseline, and married/living as married at follow-up), "stayed partnered" (married/living as married at both baseline and follow-up), and "became separated/divorced/widowed" (married/living as married at baseline, and separated/divorced/widowed at followup). Those who became partnered were compared to those who stayed not partnered. Those who became separated/divorced/widowed were compared to those who stayed partnered.

\section{Parental status and parenting transitions}

At follow-up, participants reported how many biological children they had and the month and year of birth for each child. The date the participant completed the baseline questionnaire was used to determine whether each child had been born before or after the baseline assessments. Participants were then classified into one of four groups: "stayed child-free, "had first child", "had additional children", and "same number of children". If participants had their first child plus additional children since baseline, they were classified into the group "had first child". Those who stayed child-free were compared to those who had their first child. Those who had additional children were compared to those who had the same number of children.

\section{Anthropometric measurements}

At baseline, weight $(\mathrm{kg})$ and height $(\mathrm{cm})$ were objectively measured at study clinics for most participants $(n=$ $2410)$ by trained clinic staff. A subsample $(n=1185)$ of these participants also self-reported their weight and height before measurements were taken by clinic staff to assess the accuracy of self-reported values. Clinic weight and height measures were used to predict the difference between self-reported and clinic weight and height. A correction factor that gave estimates of clinic weight and height from self-reported values was obtained from a linear regression model [24]. Participants who did not visit a study clinic $(n=1565)$ self-reported their weight and height and the correction factor was applied to adjust for error. Body mass index (BMI, $\mathrm{kg} / \mathrm{m}^{2}$ ) was calculated from height and weight. The agreement between selfreported and clinic BMI categories was high in men $(\kappa=0.80)$ and women $(\kappa=0.82)$ [24].

Weight was self-reported at follow-up. Adjusted weight values were calculated using the correction factor applied at baseline [24]. BMI was calculated using adjusted height at baseline and adjusted weight at follow-up. 


\section{PA and sedentary behaviours assessment}

Domain-specific PA and time spent sitting were measured using the long version of the International Physical Activity Questionnaire (IPAQ-L) [25]. Participants were asked to report the total time (mins) and frequency (times/week) of occupational, domestic, transport and leisure time PA during the past week. Minutes/week spent in each domain were calculated by multiplying frequency by duration. Times spent doing PA in each domain were summed to estimate the total PA (mins/ week). Time spent sitting was reported for a typical weekday and weekend day. The average daily sitting time (mins/day) was calculated by summing time spent sitting on weekdays and weekend days and dividing by seven. Daily TV viewing time (mins/day) in the past week was estimated from self-reported total time spent watching TV, digital video disks, or videocassettes (prevalent at the time the survey was conducted) on weekdays and weekend days as described in detail elsewhere [26].

\section{Covariates}

Socio-demographic information was self-reported at baseline, including age, sex, highest level of education, occupation and diet quality. Diet quality was assessed using a validated dietary guidelines index (DGI) which measures compliance with the 2013 Australian Dietary Guidelines. The DGI has a potential score range of $0-$ 100, with higher scores reflecting better diet quality [27]. Follow-up duration was calculated from the dates the participant completed the baseline and follow-up questionnaires. Parenting transitions were considered as a covariate in the analyses of partnering transitions and vice versa.

\section{Statistical analyses}

Descriptive statistics, including Mean (Standard Deviation (SD)) for continuous variables and \% (n) for categorical variables, were used to report the characteristics of participants and changes in marital and parental status, weight, PA and sedentary behaviours. Paired t-tests were used to examine whether mean scores of weight, PA and sedentary behaviours differed significantly between baseline and follow-up. Mean differences in weight, PA and sedentary behaviours at follow-up by partnering and parenting transitions were calculated separately using linear regression, adjusted for the baseline value of the outcome variable. Student $t$-tests and chisquare tests were used to compare differences in means and proportions of characteristics at the initial 1985 assessment and baseline between respondents and nonrespondents.

Covariates were considered as potential confounders if they were causally related to the outcome according to prior knowledge, imbalanced between the exposure groups and caused a change of $10 \%$ or more in the estimated effect size when included in a given regression model.

We separated men and women for the analyses because sex differences were expected and of interest. In addition, interactions between sex and partnering or parenting transitions on changes in weight, domain-specific PA and sedentary behaviours were investigated in regression models. A statistically significant sex interaction was present for the association of partnering transition with changes in moderate intensity PA $(P=0.014)$ and sitting time $(P=0.002)$ and was present for the associations of parenting transition with BMI $(P=0.030)$, moderate intensity $(P=0.002)$, occupational $(P=0.001)$ and domestic PA $(P<0.001)$ and sitting time $(P<0.001)$. To be consistent across all models, the analyses were sex stratified.

Sensitivity analyses were conducted using combined multiple imputation (MI) and inverse probability weighting (IPW) to examine the effects of loss to follow-up on the results [28]. Age, sex and school type in 1985 ASHFS were used to impute missing data and the following factors in the 1985 ASHFS were used in the calculation of the weights used in IPW to account for the loss to follow-up: height $(\mathrm{cm})$, weight $(\mathrm{kg})$, arm girth $(\mathrm{cm})$, waist girth $(\mathrm{cm})$, hip girth $(\mathrm{cm})$, sit and reach $(\mathrm{cm})$, sit-ups (number), standing long jump ( $\mathrm{cm})$, time spent to complete a $1.6 \mathrm{~km}$ run (minutes: seconds), time spent to complete a $50 \mathrm{~m}$ run (seconds), area level disadvantage, school enjoyment, school assessed and self-reported scholastic ability [23, 29]. Second, we repeated the weight analyses by excluding women who had their baby in the last 3 months $(n=30)$ as they probably still had some extra weight gain from pregnancy.

All analyses were performed with STATA software, version 12.1 (Stata Corp, College Station, Texas 77,845 USA). A two-tailed $P$ value less than 0.05 was considered statistically significant.

\section{Results}

Analyses were restricted to participants with complete information on the outcomes, exposures and confounders, leading to different sample sizes for the analyses of weight change $(n=2124)$, and PA and sedentary behaviours $(n=1221)$ (Fig. 1).

Compared with participants who were not included in the analyses, those who were included were more likely to be younger, female, more highly educated and employed as professionals or managers, married or living as married and had children at baseline (CDAH-1). There was no statistically significant difference between the two groups in baseline weight.

Using data from the initial childhood assessment, we also explored the extent to which the adult cohort 


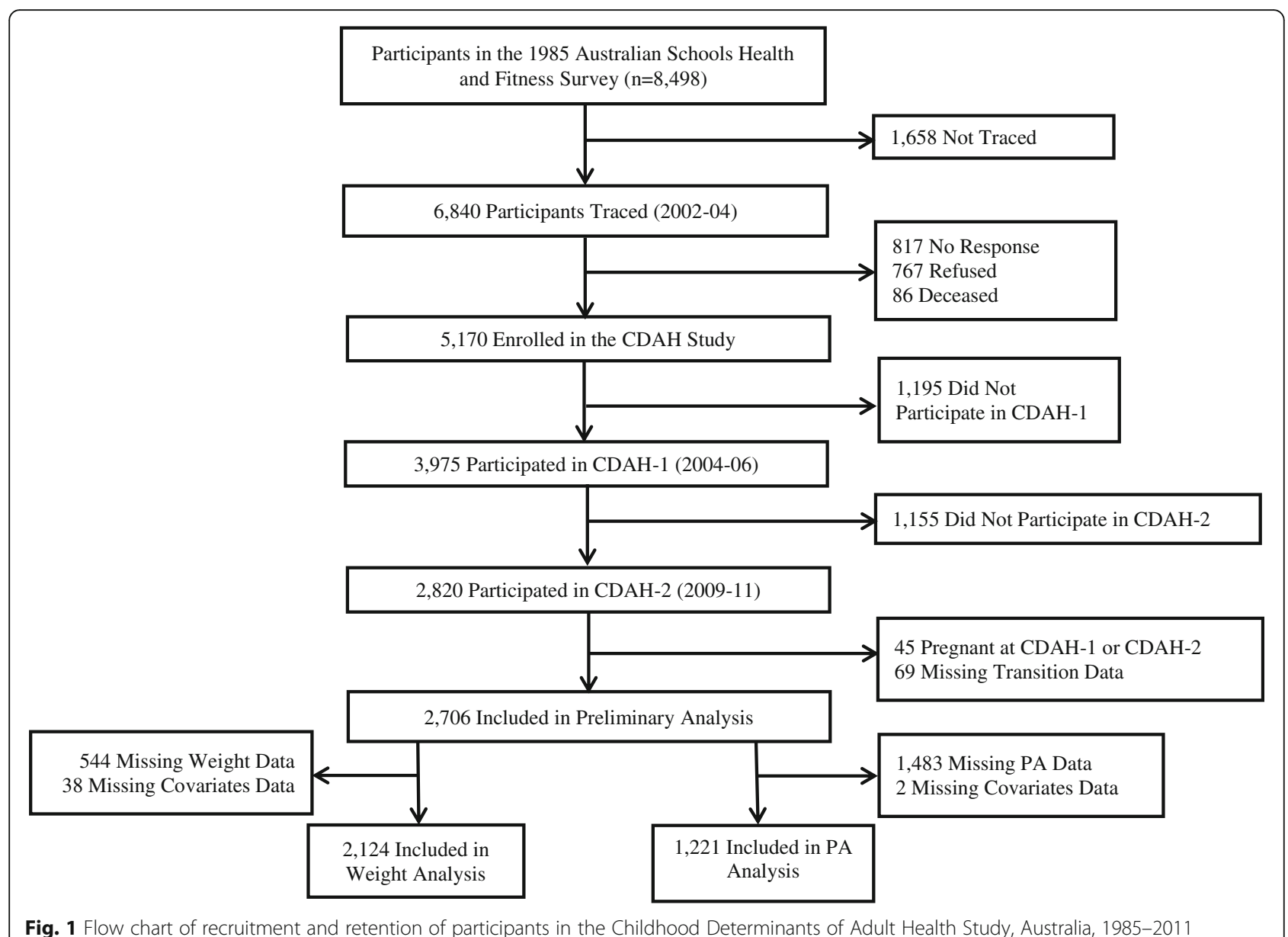

represented the childhood sample. As shown in Table S1, those who were assessed in CDAH-1 $(n=3975)$ tended to be older, more likely to be female, of higher area-level socioeconomic position and healthier than those not assessed $(n=4523)$ as indicated by their greater prevalence of healthy weight status, greater height, and better self-reported health and performance in a range of fitness measures.

The socio-demographic characteristics of participants are shown in Table 1. At baseline, $67.9 \%$ of men and $71.8 \%$ of women were married or living as married and $42.2 \%$ of men and $53.1 \%$ of women had children. Compared with the Australian general population of adults aged 25-34 years, a higher percentage of CDAH participants at baseline were married or living as married (55.6\% vs. $67.9 \%$ for men and $64.0 \%$ vs. $71.8 \%$ for women) [30] and employed as professionals or managers (33.9\% vs. $60.2 \%$ for men and $42.7 \%$ vs. $51.3 \%$ for women) [31]. No significant difference was observed for the proportion classified as overweight or obese (BMI $\geq$ $\left.25 \mathrm{~kg} / \mathrm{m}^{2}\right)(64.6 \%$ vs. $60.9 \%$ for men and $43.2 \%$ vs. $38.4 \%$ for women) [32] and the proportion categorised as child-free (for women only, $49.7 \%$ vs. $46.9 \%$ ) [33].
The changes in marital and parental status, weight, domain-specific PA and sedentary behaviours from baseline to follow-up are presented in Table 2. Over the 5year follow-up period, $17.3 \%$ of men and $12.9 \%$ of women became partnered and $27.3 \%$ of men and $19.1 \%$ of women had their first child. During follow-up, there were statistically significant increases in weight, BMI and domestic PA for both men and women. Occupational PA significantly decreased among men over the 5-year follow-up. For women only, there was a significant increase in moderate intensity PA and a decrease in sitting time over the follow-up.

Weight increased among all partnering transition groups during the 5-year period (Table S2). As shown in Table 3, after adjusting for age, sex, education and weight at baseline, follow-up length and parenting transitions, women who became partnered were, on average, $1.8 \mathrm{~kg}$ or $0.7 \mathrm{~kg} / \mathrm{m}^{2}$ heavier than those who stayed not partnered. This association was absent among men. There was no significant difference in weight and BMI at follow-up between those who stayed partnered and those who became separated/divorced/widowed. 
Table 1 Characteristics of participants at baseline (2004-06), Childhood Determinants of Adult Health Study, Australia

\begin{tabular}{|c|c|c|}
\hline Characteristics & Men $(\boldsymbol{N}=1008)^{\mathbf{a}}$ & Women $(\boldsymbol{N}=1116)^{\mathbf{a}}$ \\
\hline Age (years), Mean (SD) & $31.8(2.7)$ & $31.6(2.7)$ \\
\hline Height (cm), Mean (SD) & $179.8(6.79)$ & $166.0(6.6)$ \\
\hline Weight (kg), Mean (SD) & $85.3(14.4)$ & $68.9(14.7)$ \\
\hline \multicolumn{3}{|l|}{ Weight status, \% (n) } \\
\hline Normal & 39.1 (394) & $61.6(687)$ \\
\hline Overweight & $46.4(468)$ & $24.4(272)$ \\
\hline Obese & $14.5(146)$ & $14.1(157)$ \\
\hline \multicolumn{3}{|l|}{ Education, \% (n) } \\
\hline Any university education & $37.3(376)$ & $46.6(520)$ \\
\hline Vocational training & $36.0(363)$ & $25.5(285)$ \\
\hline High school only & $26.7(269)$ & $27.9(311)$ \\
\hline \multicolumn{3}{|l|}{ Occupation, \% (n) } \\
\hline Professional or manager & $60.2(465)$ & $51.3(456)$ \\
\hline Non-manual & $7.2(56)$ & $27.0(240)$ \\
\hline Manual & $29.2(226)$ & $4.4(39)$ \\
\hline Not in the workforce & $3.4(26)$ & $17.3(154)$ \\
\hline \multicolumn{3}{|l|}{ Marital status, \% (n) } \\
\hline Single & $29.5(297)$ & $24.7(276)$ \\
\hline Married/living as married & $67.9(684)$ & $71.8(801)$ \\
\hline Separated/divorced/Widowed & $2.7(27)$ & $3.5(39)$ \\
\hline \multicolumn{3}{|l|}{ Parental status, \% (n) } \\
\hline Child-free & $57.8(583)$ & $46.9(523)$ \\
\hline Has child (ren) & $42.2(425)$ & $53.1(593)$ \\
\hline
\end{tabular}

SD, standard deviation; BMI, body mass index

a Because of missing data, numbers do not always equal the total

Total PA decreased among all partnering transition groups except for men and women who became separated/divorced/widowed and women who stayed partnered (Table S2). Compared to men who stayed not partnered, men who became partnered reported higher levels of total, moderate intensity and domestic PA at follow-up. Partnering transitions had little effect on women's total and domain-specific PA at follow-up. There were no significant differences in sedentary behaviours at follow-up across partnering transition groups among men or women.

Weight increased among all parental groups over the 5-year follow-up (Table S3). Relative to staying childfree, having a first child was associated with greater weight and BMI at follow-up among women (Table 4). There was no significant difference in weight or BMI at follow-up between those who had the same number of children and those who had additional children.

Among men, those who had their first child during follow-up reported $123.9 \mathrm{~min} /$ week less total PA at follow-up than those who remained child-free $(P=$
Table 2 Changes in marital and parental status, weight, domain-specific physical activity and sedentary behaviours from baseline (2004-06) to follow-up (2009-11), Childhood Determinants of Adult Health Study, Australia, 1985-2011

\begin{tabular}{|c|c|c|}
\hline Variables & Men & Women \\
\hline \multicolumn{3}{|l|}{ Change in marital status, \% (n) } \\
\hline Stayed not partnered & $14.9(150)$ & $15.3(171$ \\
\hline Became partnered & $17.3(174)$ & $12.9(144$ \\
\hline Stayed partnered & $64.0(645)$ & $66.6(743$ \\
\hline $\begin{array}{l}\text { Became separated/divorced/ } \\
\text { widowed }\end{array}$ & $3.9(39)$ & $5.2(58)$ \\
\hline
\end{tabular}

Change in parental status, \% (n)

$\begin{array}{lll}\text { Stayed child-free } & 30.6(308) & 27.7(309) \\ \text { Had first child } & 27.3(275) & 19.1(213) \\ \text { Had additional children } & 19.4(196) & 19.0(212) \\ \text { Same number of children } & 22.7(229) & 34.2(382)\end{array}$

Weight (kg), Mean (SD)

$\begin{array}{lll}\text { Baseline } & 85.3(14.4) & 68.9(14.7) \\ \text { Follow-up } & 87.8(15.2)^{* * * a} & 71.4(15.7)^{* * * a} \\ \left.\text { BMI (kg/m }{ }^{2}\right) \text {, Mean (SD) } & & \\ \text { Baseline } & 26.4(4.1) & 25.0(5.1) \\ \text { Follow-up } & 27.2(4.7)^{* * * a} & 25.8(5.6)^{* * * a}\end{array}$

Total PA (mins/wk), Mean (SD)

Baseline

$738.0(529.9) \quad 703.9(462.8)$

Follow-up

$699.9(503.1)$

$741.3(476.0)$

Walking PA (mins/wk), Mean (SD)

\section{Baseline}

$262.9(280.8)$

$245.4(243.8)$

Follow-up

$237.9(260.9)$

$243.1(259.5)$

Moderate intensity PA (mins/wk), Mean (SD)

$\begin{array}{lll}\text { Baseline } & 303.4(240.5) & 376.9(315.7) \\ \text { Follow-up } & 306.6(244.6) & 415.8(328.0)^{* * a}\end{array}$

Vigorous intensity PA (mins/wk), Mean (SD)

$\begin{array}{lll}\text { Baseline } & 171.8(222.2) & 81.6(155.5) \\ \text { Follow-up } & 155.4(202.2) & 82.4(129.4)\end{array}$

Occupational PA (mins/wk), Mean (SD)

$\begin{array}{lll}\text { Baseline } & 285.3(394.8) & 146.3(290.4) \\ \text { Follow-up } & 241.6(355.6)^{* a} & 127.0(252.4)\end{array}$

Transport PA (mins/wk), Mean (SD)

$\begin{array}{lll}\text { Baseline } & 109.4(163.7) & 105.4(150.5) \\ \text { Follow-up } & 103.0(145.9) & 103.4(166.3)\end{array}$

Domestic PA (mins/wk), Mean (SD)

$\begin{array}{lll}\text { Baseline } & 160.6(167.8) & 302.2(307.4) \\ \text { Follow-up } & 188.2(193.5)^{* * a} & 351.1(321.4)^{* * * a}\end{array}$

Leisure time PA (mins/wk), Mean (SD)

$\begin{array}{lll}\text { Baseline } & 182.7(232.2) & 150.0(177.6) \\ \text { Follow-up } & 167.1(195.5) & 159.9(175.3)\end{array}$


Table 2 Changes in marital and parental status, weight, domain-specific physical activity and sedentary behaviours from baseline (2004-06) to follow-up (2009-11), Childhood Determinants of Adult Health Study, Australia, 1985-2011 (Continued)

\begin{tabular}{lll}
\hline Variables & \multicolumn{1}{l}{ Men } & Women \\
\hline Sitting time (mins/day), Mean (SD) & & \\
Baseline & $369.9(180.0)$ & $326.0(162.5)$ \\
Follow-up & $364.5(184.9)$ & $297.3(159.2)^{* * * a}$ \\
TV viewing time (mins/day), Mean (SD) & \\
Baseline & $125.8(90.6)$ & $102.2(72.6)$ \\
Follow-up & $128.2(92.6)$ & $100.8(70.0)$
\end{tabular}

$\mathrm{SD}$, standard deviation; BMI, body mass index; PA, physical activity

a There was statistically significant difference compared to baseline value, $P$ value was calculated using Paired t-test

${ }^{*} P \leq 0.05,{ }^{* *} P \leq 0.01,{ }^{* * *} P \leq 0.001$

0.052), independent of baseline value and other confounders (Table 4). They spent less time in walking, vigorous intensity, transport, and leisure time $\mathrm{PA}$ at follow-up.

During the 5-year follow-up, time spent sitting and watching TV decreased among all parental groups except the group remaining child-free (Table S3). Relative to staying child-free, transition into parenthood with a first child was associated with $26.4 \mathrm{~min} /$ day less TV viewing time at follow-up among men and $103.4 \mathrm{~min} /$ day less sitting time at follow-up among women. For women only, having additional children was associated with $39.3 \mathrm{~min} /$ day less sitting time at follow-up than having the same number of children.

In sensitivity analyses to examine the effects of loss to follow-up on results, similar findings to those reported in Tables 3 and 4 were observed when applying combined MI and IPW (data not shown). The results obtained after excluding women who had their baby in the last 3 months were broadly similar to the original results in direction and magnitude (the change in $\beta$ coefficient ranged from -10.6 to $43.5 \%$, Table S4), but the statistically significant greater weight gain for women having their first child relative to those staying child-free was no longer apparent ( $\beta, 95 \% \mathrm{CI}: 0.8,-0.5$ to 2.1$)$.

\section{Discussion}

In this longitudinal study of Australian adults, we found that the associations of partnering and parenting transitions with changes in weight, domain-specific PA and sedentary behaviours differed between men and women. Compared to remaining not partnered, partnering was associated with an increase in total PA among men and a greater weight gain among women. Men who had their first child reported greater reductions in total PA and TV viewing time than those remaining child-free. Women having a first child had greater weight gain but spent less time sitting than those remaining child-free. Having additional children was associated with less sitting time than having the same number of children among women.

We found that partnering and parenting transitions were differentially associated with changes in weight among men and women. Greater weight gain was observed among women who became partnered than those who stayed not partnered and among women who had first child than those who stayed child-free, while no significant differences were observed among men. These results are supported by some longitudinal studies [20, $34]$ but not others $[5,16]$. The attractiveness model may help to explain the greater weight gain associated with transition to partnership in women only. In a survey of preferred traits in a relationship partner, physical attractiveness was rated as being more important by men than women [35] and weight is one of the important physical attractiveness characteristics. Partnered people may be less likely to be concerned about their weight because they are not in marriage market [36]. Another possible reason for the sex difference is that, as we found, men who became partnered tended to be more active compared to their counterparts who stayed unpartnered while there was no significant difference between these two groups among women. Excluding women who recently had a baby took away the statistically significant greater weight gain among those who had their first child than those who stayed child-free, suggesting a short-term weight gain after giving birth.

The benefits of partnering on PA levels were greater for men than women. Men who became partnered showed higher total PA at follow-up than those who stayed not partnered. They tended to increase their domestic PA and moderate intensity PA during follow-up. Partnering transitions appeared to have little effect on women's PA though women who became separated/divorced/widowed had higher transport PA at follow-up than their peers who remained partnered. To the authors' knowledge, this is the first longitudinal report of change in total PA by partnering transitions among men. Several studies of similar design among men all focused on leisure time PA [16-19, 37, 38] and only one of them examined participants in their 20s when partnering often takes place [18]. Our finding of no significant difference in men's leisure time PA by partnering transitions is supported by this comparable study [18]. The greater PA benefits of partnership to men than women may be partly explained by gender and marital roles. Compared to men, women are generally more knowledgeable of health-related issues and are more likely to assume responsibility for health of their partners and encourage them to conform to health norms $[19,39]$, such as being more active. 
Table $3 \beta(95 \%$ Cl) for weight, domain-specific physical activity and sedentary behaviours by change in marital status, Childhood Determinants of Adult Health Study, Australia, 1985-2011

\begin{tabular}{|c|c|c|c|c|c|c|}
\hline \multirow[t]{3}{*}{ Variables } & \multicolumn{3}{|l|}{ Men } & \multicolumn{3}{|c|}{ Women } \\
\hline & \multirow[t]{2}{*}{$\mathrm{n}$} & \multirow{2}{*}{$\begin{array}{l}\text { Model } 1 \\
\beta(95 \% \mathrm{Cl})\end{array}$} & \multirow{2}{*}{$\begin{array}{l}\text { Model } 2 \\
\beta(95 \% \text { Cl) }\end{array}$} & \multirow[t]{2}{*}{$\bar{n}$} & \multirow{2}{*}{$\begin{array}{l}\text { Model } 1 \\
\beta(95 \% \mathrm{Cl})\end{array}$} & \multirow{2}{*}{$\begin{array}{l}\text { Model } 2 \\
\beta(95 \% \mathrm{Cl})\end{array}$} \\
\hline & & & & & & \\
\hline \multicolumn{7}{|l|}{ Weight (kg) } \\
\hline Stayed not partnered & 150 & REF & REF & 171 & REF & REF \\
\hline Became partnered & 174 & $0.7(-0.9,2.2)$ & $1.1(-0.5,2.8)$ & 144 & $2.2(0.7,3.7)^{* *}$ & $1.8(0.2,3.4)^{*}$ \\
\hline Stayed partnered & 645 & REF & REF & 743 & REF & REF \\
\hline Became separated/divorced/widowed & 39 & $-1.3(-3.6,0.9)$ & $-1.6(-3.9,0.7)$ & 58 & $-1.0(-2.9,0.8)$ & $-1.1(-2.9,0.8)$ \\
\hline \multicolumn{7}{|l|}{$\mathrm{BMI}\left(\mathrm{kg} / \mathrm{m}^{2}\right)$} \\
\hline Stayed not partnered & 150 & REF & REF & 171 & REF & REF \\
\hline Became partnered & 174 & $-0.1(-0.6,0.5)$ & $0.1(-0.5,0.6)$ & 144 & $0.9(0.3,1.4)^{* *}$ & $0.7(0.1,1.3)^{*}$ \\
\hline Stayed partnered & 645 & REF & REF & 743 & REF & REF \\
\hline Became separated/divorced/widowed & 39 & $-0.4(-1.2,0.3)$ & $-0.5(-1.3,0.3)$ & 58 & $-0.5(-1.2,0.2)$ & $-0.5(-1.2,0.2)$ \\
\hline \multicolumn{7}{|l|}{ Total PA (mins/wk) } \\
\hline Stayed not partnered & 56 & REF & REF & 123 & REF & REF \\
\hline Became partnered & 84 & $101.9(-51.6,255.5)$ & $175.3(17.2,333.4)^{*}$ & 78 & $84.5(-41.7,210.7)$ & $65.5(-65.4,196.4)$ \\
\hline Stayed partnered & 276 & REF & REF & 554 & REF & REF \\
\hline Became separated/divorced/widowed & 16 & $54.6(-174.1,283.4)$ & $46.8(-184.1,277.8)$ & 34 & $67.4(-86.8,221.6)$ & $82.7(-73.3,238.8)$ \\
\hline \multicolumn{7}{|l|}{ Walking PA (mins/wk) } \\
\hline Stayed not partnered & 56 & REF & REF & 123 & REF & REF \\
\hline Became partnered & 84 & $-2.3(-84.0,79.3)$ & $43.2(-41.0,127.5)$ & 78 & $-20.8(-92.0,50.3)$ & $10.9(-62.5,84.3)$ \\
\hline Stayed partnered & 276 & REF & REF & 554 & REF & REF \\
\hline Became separated/divorced/widowed & 16 & $47.6(-74.0,169.3)$ & $19.8(-103.2,142.9)$ & 34 & $86.3(-0.7,173.3)$ & $65.4(-22.2,153.0)$ \\
\hline \multicolumn{7}{|l|}{ Moderate intensity PA (mins/wk) } \\
\hline Stayed not partnered & 56 & REF & REF & 123 & REF & REF \\
\hline Became partnered & 84 & $88.1(9.4,166.8)^{*}$ & $86.8(4.6,169.0)^{*}$ & 78 & $101.9(16.7,187.1)^{*}$ & $37.0(-49.4,123.4)$ \\
\hline Stayed partnered & 276 & REF & REF & 554 & REF & REF \\
\hline Became separated/divorced/widowed & 16 & $-26.7(-144.0,90.6)$ & $-7.0(-127.1,113.1)$ & 34 & $3.4(-100.6,107.4)$ & $47.1(-55.7,150.0)$ \\
\hline \multicolumn{7}{|l|}{ Vigorous intensity PA (mins/wk) } \\
\hline Stayed not partnered & 56 & REF & REF & 123 & REF & REF \\
\hline Became partnered & 84 & $21.4(-44.2,86.9)$ & $51.0(-16.1,118.0)$ & 78 & $5.1(-31.1,41.3)$ & $22.2(-14.9,59.3)$ \\
\hline Stayed partnered & 276 & REF & REF & 554 & REF & REF \\
\hline Became separated/divorced/widowed & 16 & $30.4(-67.3,128.1)$ & $29.2(-68.8,127.2)$ & 34 & $-28.0(-72.2,16.2)$ & $-40.3(-84.4,3.9)$ \\
\hline \multicolumn{7}{|l|}{ Occupational PA (mins/wk) } \\
\hline Stayed not partnered & 56 & REF & REF & 123 & REF & REF \\
\hline Became partnered & 84 & $40.9(-70.5,152.3)$ & $62.0(-52.8,176.9)$ & 78 & $6.8(-62.9,76.5)$ & $45.5(-25.0,116.0)$ \\
\hline Stayed partnered & 276 & REF & REF & 554 & REF & REF \\
\hline Became separated/divorced/widowed & 16 & $-84.9(-250.9,81.2)$ & $-70.9(-238.7,96.9)$ & 34 & $-8.4(-93.4,76.6)$ & $-46.8(-130.7,37.1)$ \\
\hline \multicolumn{7}{|l|}{ Transport PA (mins/wk) } \\
\hline Stayed not partnered & 56 & REF & REF & 123 & REF & REF \\
\hline Became partnered & 84 & $14.0(-34.0,62.0)$ & $32.8(-17.2,82.8)$ & 78 & $-40.6(-86.7,5.4)$ & $-38.4(-86.0,9.3)$ \\
\hline Stayed partnered & 276 & REF & REF & 554 & REF & REF \\
\hline Became separated/divorced/widowed & 16 & $55.7(-15.9,127.2)$ & $44.8(-28.2,117.9)$ & 34 & $57.3(1.1,113.5)^{*}$ & $62.0(5.3,118.8)^{*}$ \\
\hline
\end{tabular}


Table $3 \beta$ (95\% Cl) for weight, domain-specific physical activity and sedentary behaviours by change in marital status, Childhood Determinants of Adult Health Study, Australia, 1985-2011 (Continued)

\begin{tabular}{|c|c|c|c|c|c|c|}
\hline \multirow[t]{3}{*}{ Variables } & \multicolumn{3}{|l|}{ Men } & \multicolumn{3}{|c|}{ Women } \\
\hline & \multirow[t]{2}{*}{$\mathrm{n}$} & \multirow{2}{*}{$\begin{array}{l}\text { Model } 1 \\
\beta(95 \% \mathrm{Cl})\end{array}$} & \multirow{2}{*}{$\begin{array}{l}\text { Model } 2 \\
\beta(95 \% \text { Cl) }\end{array}$} & \multirow[t]{2}{*}{$\mathrm{n}$} & \multirow{2}{*}{$\begin{array}{l}\text { Model } 1 \\
\beta(95 \% \mathrm{Cl})\end{array}$} & \multirow{2}{*}{$\begin{array}{l}\text { Model } 2 \\
\beta(95 \% \mathrm{Cl})\end{array}$} \\
\hline & & & & & & \\
\hline \multicolumn{7}{|l|}{ Domestic PA (mins/wk) } \\
\hline Stayed not partnered & 56 & REF & REF & 123 & REF & REF \\
\hline Became partnered & 84 & $100.2(37.5,162.9)^{* *}$ & $96.7(30.8,162.7)^{* *}$ & 78 & $129.3(46.4,212.1)^{* *}$ & $47.3(-35.2,129.8)$ \\
\hline Stayed partnered & 276 & REF & REF & 554 & REF & REF \\
\hline Became separated/divorced/widowed & 16 & $-13.1(-106.5,80.4)$ & $-5.3(-101.7,91.1)$ & 34 & $18.5(-82.6,119.7)$ & $75.7(-22.5,173.9)$ \\
\hline \multicolumn{7}{|l|}{ Leisure time PA (mins/wk) } \\
\hline Stayed not partnered & 56 & REF & REF & 123 & REF & REF \\
\hline Became partnered & 84 & $-45.9(-106.8,14.9)$ & $-8.8(-71.8,54.2)$ & 78 & $-5.2(-52.8,42.3)$ & $19.7(-28.9,68.4)$ \\
\hline Stayed partnered & 276 & REF & REF & 554 & REF & REF \\
\hline Became separated/divorced/widowed & 16 & $93.0(2.3,183.6)^{*}$ & $70.4(-21.7,162.4)$ & 34 & $-8.8(-66.7,49.0)$ & $-22.7(-80.6,35.2)$ \\
\hline \multicolumn{7}{|l|}{ Sitting time (mins/day) } \\
\hline Stayed not partnered & 56 & REF & REF & 123 & REF & REF \\
\hline Became partnered & 84 & $3.7(-50.0,57.3)$ & $5.0(-50.3,60.3)$ & 78 & $-43.3(-83.0,-3.5)^{*}$ & $-5.1(-44.8,34.6)$ \\
\hline Stayed partnered & 276 & REF & REF & 554 & REF & REF \\
\hline Became separated/divorced/widowed & 16 & $-34.3(-114.3,45.7)$ & $-49.4(-130.4,31.5)$ & 34 & $50.0(1.7,98.3)^{*}$ & $27.8(-19.2,74.8)$ \\
\hline \multicolumn{7}{|l|}{ TV viewing time (mins/day) } \\
\hline Stayed not partnered & 56 & REF & REF & 123 & REF & REF \\
\hline Became partnered & 84 & $-5.6(-34.2,23.0)$ & $4.5(-25.4,34.5)$ & 78 & $-6.6(-24.8,11.6)$ & $-4.2(-23.1,14.6)$ \\
\hline Stayed partnered & 276 & REF & REF & 554 & REF & REF \\
\hline Became separated/divorced/widowed & 16 & $31.9(-10.7,74.6)$ & $25.0(-18.8,68.8)$ & 34 & $-13.3(-35.6,9.0)$ & $-15.9(-38.4,6.5)$ \\
\hline
\end{tabular}

$\mathrm{BMI}$, body mass index; $\mathrm{Cl}$, confidence interval; PA, physical activity

Model 1: adjusted for weight, PA or sedentary behaviours at baseline

Model 2: Model $1+$ baseline age, sex, education, follow-up length and parenting transitions

$\beta(95 \% \mathrm{Cl})$ in bold means statistically significant difference compared to the reference group (became partnered vs. stayed not partnered, became separated/

divorced/widowed vs. stayed partnered both times)

${ }^{*} P \leq 0.05,{ }^{* *} P \leq 0.01$

Compared to men who stayed child-free, men who had their first child decreased their total PA $(P=0.052)$. They tended to decrease their walking, vigorous intensity, transport and leisure time PA more than those who remained child-free. Although no significant difference in total PA at follow-up was observed between these two groups among women, there were both healthy and unhealthy changes in PA by intensity and domain as detailed in results. Only one previous study has attempted to explore how sex moderates the longitudinal relationship between parenting transitions and PA, but that study only assessed leisure time PA [18]. Our finding in men is supported by this study but not the results in women [18]. The inconsistent finding in women may be because that study only had a small number of women who had their first child $(n=16)$ and included a high proportion of pregnant women at baseline [22]. It is well documented that pregnancy is a period of decreased PA [40].
Relative to having the same number of children, having additional children had little effect on men's PA but was associated with both increases and reductions in women's PA by intensity and domain, despite no significant change in total PA. These results are consistent with prior evidence in men [18] and women $[12,14,18]$ but all previous studies only assessed leisure time PA. Time constraints and being out of the work force may help to explain the significant reduction in occupational PA and increases in domestic and moderate intensity PA among women compared with men. This speculation was supported by Australian and international research. In a large-scale, longitudinal and nationally representative study of children and families from Australia, highly gendered patterns in the time-use distribution of parents of young children were found. Fathers spent more time than mothers in paid employment, but less time caring for children and domestic work [41]. Similar results were reported in studies from other countries [42]. Even when 


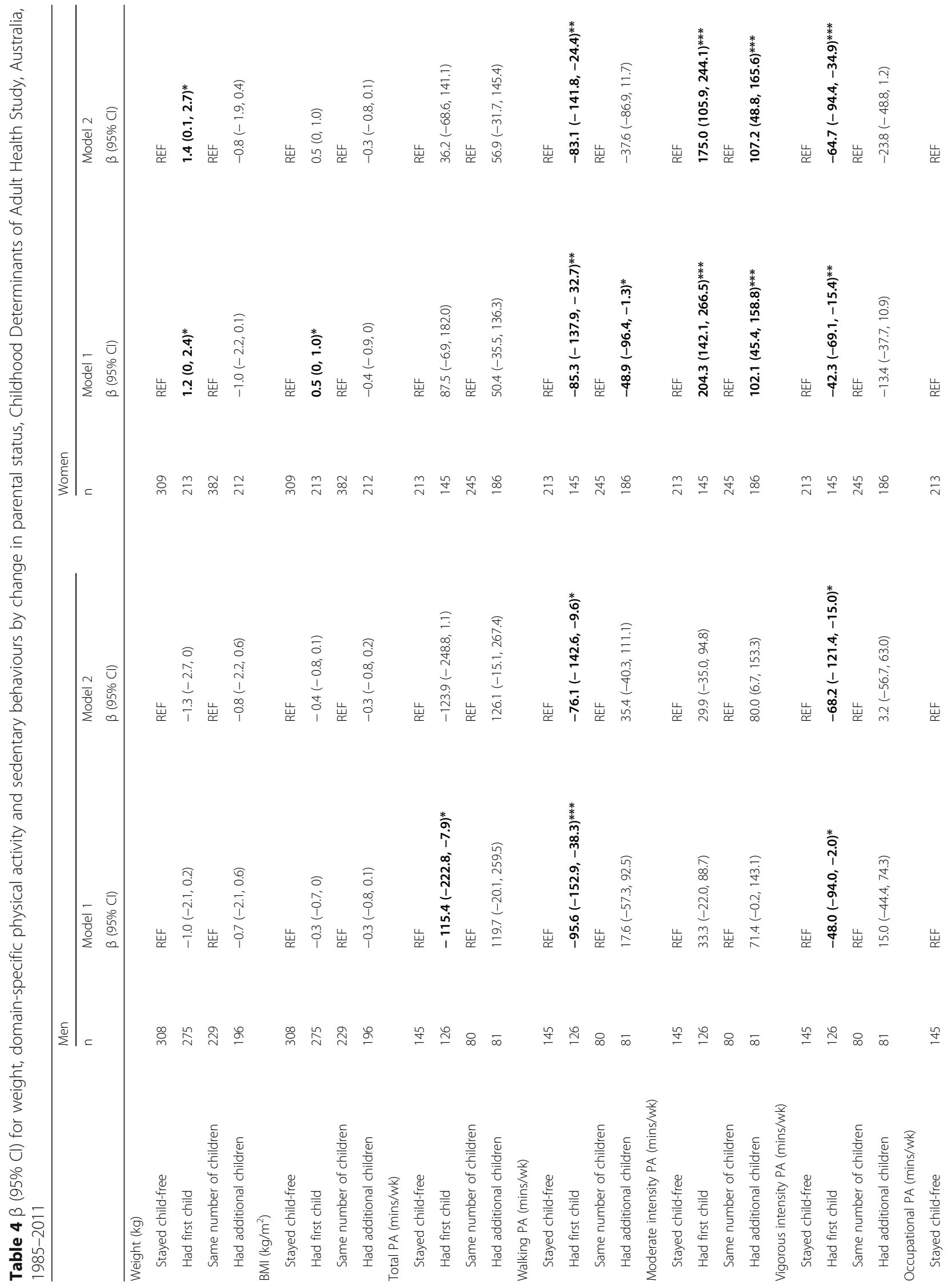




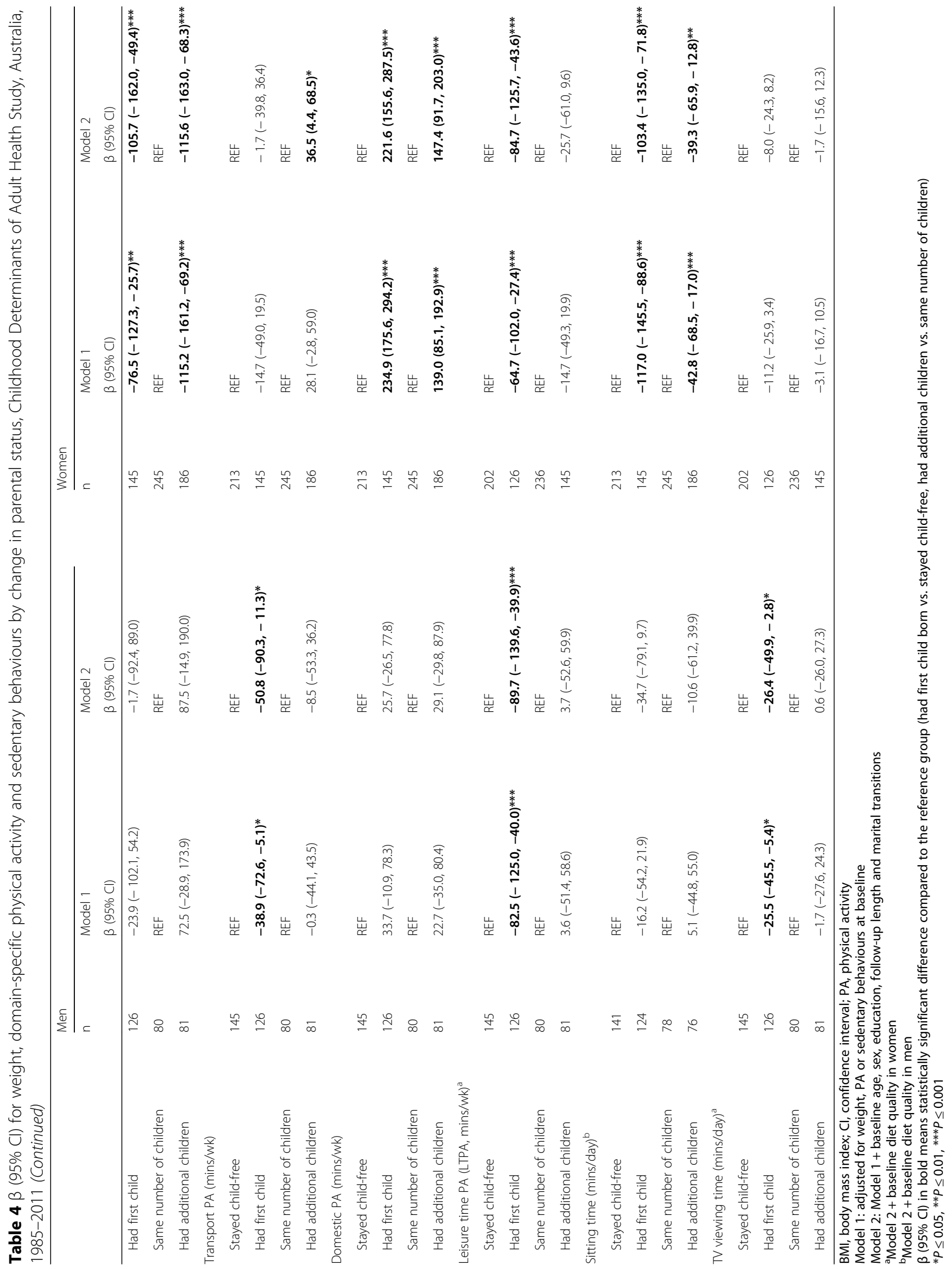


both parents undertook full-time paid work, mothers continued to do more child care and house work [43]. Having additional children can further change women's time and energy commitments, such as spending less time in work and leisure time PA and more time in domestic PA, as seen in this study.

Having a first child was associated with less sitting time in women and less TV viewing time in men than remaining child-free. The finding is consistent with previous cross-sectional studies conducted in Australia [44] and Canada [45], which showed an inverse relationship between number of children and sitting time. This might be simply because child care limits time for relaxation and entertainment. Another possible explanation is change in employment status (e.g. taking maternity leave and returning to work part time). Hours worked per week have been associated with greater sitting time, with women working full time spending more time sitting [44]. Alternatively, parents may decrease their sedentary behaviours to create a health-promoting environment for their young children [46]. Having additional children was also found to be associated with less sitting time than having the same number of children among women. This might be explained by women's further time constraints and being out of the work force.

No significant differences were observed between baseline and follow-up levels of total, vigorous intensity, transport, leisure time and walking PA, and TV viewing time. Our results concur with prior evidence that suggests that mid-adulthood is a period where these PA and sedentary behaviour plateau $[47,48]$ but not all [49]. For example, using data from a nationally representative sample of adults from the US $(n=43,732)$, Caspersen et al. [47] showed that leisure time PA patterns (i.e. prevalence of physical inactivity; regular, sustained PA; and regular, vigorous PA) in mid-adulthood (30-64 years) were relatively stable and the absolute annual rates of change in all aforementioned leisure time PA patterns were less than 0.5 percentage points per year. In contrast to Caspersen and colleagues' findings, using accelerometer-measured PA in a nationally representative health survey in US, Troiano et al. [49] concluded that total PA declined with age across the lifespan although the declines in mid-adulthood were at a slower rate than in adolescence. Possible explanations for the discrepancies may include differences in PA measurements (i.e. self-reported vs. objective-measured) and types (i.e. total vs. leisure time PA), definitions of age groups (i.e. 5-year vs. 10-year) and study designs (i.e. cross-sectional vs. longitudinal).

We did not find a significant difference in sedentary behaviours at follow-up between those who experienced partnering transitions and those who did not, suggesting partnering and partnership termination do not play a role in predicting future sedentary behaviours. TV viewing time was similar between baseline and follow-up in both men and women, averaging about $2 \mathrm{~h}$ daily. This amount of time was about half of that reported from the 2006 Australian Time Use Surveys [50]. Our participants' higher education level (bachelor's degree or higher $42.2 \%$ vs. $22.1 \%$ in the general population of the same age group) and lower proportion not in labour force $(10.8 \%$ vs. $32.9 \%)$ might help to explain the difference. Although the evidence is not conclusive [51], most studies support a link between low educational attainment or not being in paid work and prolonged TV viewing time ( $\geq 2 \mathrm{~h}$ /day) [52, 53]. Growing use of other digital media (e.g. smartphone, tablet and laptop) in the period of follow-up through to 2009-11 may have contributed to changes in TV watching, but the impact on the results is likely minimal since there is no evidence that TV watching evolves differently by marital or parental status.

Some limitations should be acknowledged when interpreting the results. First, self-reported weight might underestimate the actual weight. However, we applied a correction factor to reduce the potential error, and the outcome of interest calculation - weight change based on self-reported weight from baseline to follow-up has been identified as a valid estimate with minimal error [54]. Second, there might be measurement error and recall bias in PA and sedentary behaviours as these data were collected by means of self-completed questionnaires and participants were asked to recall their PA for each domain over the past week. PA from IPAQ-L has a tendency towards over-reporting $[55,56]$ and time spent in sedentary behaviours is prone to under-reporting [57]. However, these measurements have been validated in a number of studies and are widely accepted in the literature. Although lower than device-measured sitting time (varying greatly in the literature, mostly over $9 \mathrm{~h} /$ day) [57], our estimate of sitting time (5-6h/day) is similar to other reports from the Australian general population of similar age in 2011 (males $6.4 \mathrm{~h}$ /day and females $5.3 \mathrm{~h} /$ day) [58] and some studies which also used the IPAQ-L to measure sitting time (about $6 \mathrm{~h} /$ day) [56, 59]. There is no evidence that the accuracy of selfreported PA and sedentary behaviours differs by marital and parental status. Most importantly, our outcome of interest is change in these behaviours, not data at one time point. To the extent that the errors of measurement at different time points are correlated, calculating changes in PA and sedentary behaviours should help to reduce their impact on the estimated associations. In addition, IPAQ-L only reports absolute PA time. For example, total working time is not taken into account in the calculation of occupational PA (same for other PA domains). Therefore, the observed large changes in PA 
over time could be simply due to changes in participants daily lives (e.g. becoming partnered or transition into parenthood). Third, only biological children were included in the definition of parental status. There might be misclassification of participants who adopted children or who became a step-parent. Fourth, the variable of partnering transitions was defined based on marital status at two-time points, 5-years apart. It is possible that other marital transitions have occurred during the follow-up. Besides, the increase in total PA among men and weight among women who became partnered might have been underestimated, since participants who were in a relationship but living apart were classified as single. This may have diluted the associations of partnering transitions with changes in PA and weight. However, our definition of marital status is widely used in Australian national reports [60] and the literature [61], and the proportion of Australian adults falling into this category is low (9\%) [62]. Fifth, the sample size for some sub analyses is rather small. Future larger studies are needed to confirm our findings. Last, up to two-thirds of participants were not included in the analyses of changing PA and sedentary behaviours for various reasons (e.g. loss to follow-up, being pregnant or missing information on covariates). Comparison of sociodemographic characteristics between those included and those not included revealed that participants included were more likely to be younger, female, more highly educated and employed as professionals or managers, married or living as married and had children at baseline. However, we applied combined MI and IPW to account for these differences and found the original results were largely unchanged.

The strengths of this study include its large national sample, the prospective design, the mutual adjustment for partnering and parenting transitions in analyses, the sex stratified analyses and the use of advanced methodology to account for loss to follow-up. In addition, this is the first study to examine the longitudinal relationships between two important life stage transitions in young adulthood and domain-specific PA and sedentary behaviours. This is important as these results could help to understand the domain-specific changes in PA and thereby illuminate the most opportune interventions to help mitigate the declined PA during parenthood.

\section{Conclusions}

Partnering was associated with increases in men's total PA and women's weight. Transitions into parenthood with a first child or additional children were associated with potentially health-impairing changes in weight and PA, but health-promoting changes in sedentary behaviours among men and women. Although the precise mechanisms through which greater weight gain occurs among women are likely to be complex and remain uncertain, our findings add to a growing body of evidence that women's weight is more easily influenced by partnering and parenting transitions than men's, and thus deserves specific attention in relation to obesity prevention. This study identified an important high-risk group for targeting of PA strategies - men who had their first child. To mitigate their decreased total PA, our domainspecific results suggest that future promotion strategies should focus on increasing transport and leisure time PA. Future research with objectively measured PA and sedentary time (e.g. through accelerometry) and larger samples are needed to verify our findings.

\section{Supplementary information}

Supplementary information accompanies this paper at https://doi.org/10. 1186/s12966-020-00989-6.

Additional file 1: Table S1. Childhood characteristics of participants assessed and not assessed at baseline in adulthood, Childhood Determinants of Adult Health Study, Australia, 1985-2011 a. Table S2. Mean and standard deviation for weight, domain-specific physical activity and sedentary behaviours at baseline and follow-up by change in marital status, Childhood Determinants of Adult Health Study, Australia, 19852011. Table S3. Mean and standard deviation for weight, domainspecific physical activity and sedentary behaviours at baseline and followup by change in parental status, Childhood Determinants of Adult Health Study, Australia, 1985-2011. Table S4. $\beta$ (95\% Cl) for weight by change in parental status before or after removing women who had their baby in the last 3 months, Childhood Determinants of Adult Health Study, Australia, 1985-2011.

\section{Abbreviations}

ASHFS: Australian Schools Health and Fitness Survey; BMI: Body Mass Index; CDAH: Childhood Determinants of Adult Health; Cl: Confidence Interval; IPAQ: International Physical Activity Questionnaire; IPW: Inverse Probability Weighting; METs: Metabolic Equivalents; MI: Multiple Imputation; PA: Physical Activity; SD: Standard Deviation; TV: Television; US: United States

\section{Acknowledgements}

We greatly acknowledge the contributions of study project manager, Marita Dalton, and all other project staff.

\section{Authors' contributions}

JT: study design, data analyses and interpretation, manuscript writing and revision. KJS, VC and SG: data interpretation and manuscript revision. TD: study conceptualisation and manuscript revision. AV: study conceptualisation, data acquisition and interpretation, and manuscript revision. The author(s) read and approved the final manuscript.

\section{Funding}

This study was supported by Grants from the National Health and Medical Research Council (NHMRC 211316 and 544923), the National Heart Foundation (GOOH0578), the Tasmanian Community Fund and Veolia Environmental Services. We gratefully acknowledge the study sponsors Sanitarium, ASICS and Target. KJS was supported by NHMRC Early Career Fellowship (1072516). SG (100446) and VC (100444) were supported by National Heart Foundation of Australia Future Leader Fellowships. Funding bodies and sponsors did not play a role in the study design, collection, analysis, or interpretation of data, in the writing of the manuscript, or the decision to submit the manuscript for publication.

\section{Availability of data and materials}

The datasets used and/or analysed during the current study are available from the corresponding author on reasonable request. 


\section{Ethics approval and consent to participate}

The study protocol was approved by the Southern Tasmanian Health and Medical Ethics Committee (ethics approval number: H0006020 at baseline and H0010454 at follow-up). Written informed consent was obtained from all participants included in the study at both time points.

\section{Consent for publication}

Not applicable.

\section{Competing interests}

The authors declare that they have no competing interests.

\section{Author details}

'Menzies Institute for Medical Research, University of Tasmania, 17 Liverpool Street, Hobart, Tasmania 7000, Australia. ${ }^{2}$ The George Institute for Global Health, University of Oxford, Wellington Square, Oxford, UK.

\section{Received: 6 October 2019 Accepted: 26 June 2020}

\section{Published online: 08 July 2020}

\section{References}

1. Marriages and Divorces, Australia, 2016. [database on the Internet]. ABS. 2017. Available from: https://www.abs.gov.au/ausstats/abs@.nsf/ Previousproducts/3310.0Main\%20Features112016 ?opendocument \&tabname=Summary\&prodno=3310.0\&issue $=2016 \&$ num $=$ \&view=. Accessed 30 July 2018.

2. Marriages and Divorces, Australia, 2008 [database on the Internet]. ABS. 2009. Available from: http://www.abs.gov.au/ausstats/abs@.nsf/Products/ EBD38066BE7A7FA8CA25762000159DCF?opendocument. Accessed: 30 July 2017.

3. Australia's mothers and babies 1993. AlHW National Perinatal Statistics Unit: Perinatal Statistics Series No. 3 [database on the Internet]. AlHW. 1996. Available from: https://www.aihw.gov.au/getmedia/02d6315a-060b-46d1b7b4-968fb685353d/Australias\%20mothers\%20and\%20babies\%201993.pdf. aspx?inline=true. Accessed: 9 September 2019.

4. Australia's mothers and babies 2017-in brief. Perinatal statistics series no. 35. Cat. no. PER 100. [database on the Internet]. AlHW. 2017. Available from: https://www.aihw.gov.au/getmedia/2a0c22a2-ba27-4ba0-ad47-ebbe51854 cd6/aihw-per-100-in-brief.pdf.aspx?inline=true. Accessed: 30 July 2018.

5. Teachman J. Body weight, marital status, and changes in marital status. J Fam Issues. 2016:37(1):74-96.

6. Sobal J, Rauschenbach B, Frongillo EA. Marital status changes and body weight changes: a US longitudinal analysis. Soc Sci Med. 2003;56(7):1543-55.

7. Gunderson EP, Abrams B. Epidemiology of gestational weight gain and body weight changes after pregnancy. Epidemiol Rev. 2000;22(2):261-74.

8. Weng HH, Bastian LA, Taylor DH Jr, Moser BK, Ostbye T. Number of children associated with obesity in middle-aged women and men: results from the health and retirement study. J Women's Health (Larchmt). 2004;13(1):85-91.

9. Saxbe D, Corner GW, Khaled M, Horton K, Wu B, Khoddam HL. The weight of fatherhood: identifying mechanisms to explain paternal perinatal weight gain. Health Psychol Rev. 2018;12(3):294-311.

10. Umberson D, Liu H, Mirowsky J, Reczek C. Parenthood and trajectories of change in body weight over the life course. Soc Sci Med. 2011;73(9): 1323-31.

11. Garfield CF, Duncan G, Gutina A, Rutsohn J, McDade TW, Adam EK, et al. Longitudinal study of body mass index in young males and the transition to fatherhood. Am J Mens Health. 2016;10(6):NP158-NP67.

12. Brown WJ, Heesch KC, Miller YD. Life events and changing physical activity patterns in women at different life stages. Ann Behav Med. 2009:37(3):294-305

13. Bell S, Lee $C$. Emerging adulthood and patterns of physical activity among young Australian women. Int J Behav Med. 2005;12(4):227-35.

14. Brown WJ, Trost SG. Life transitions and changing physical activity patterns in young women. Am J Prev Med. 2003;25(2):140-3.

15. Rapp I, Schneider B. The impacts of marriage, cohabitation and dating relationships on weekly self-reported physical activity in Germany: a 19-year longitudinal study. Soc Sci Med. 2013;98:197-203.

16. Eng PM, Kawachi I, Fitzmaurice G, Rimm EB. Effects of marital transitions on changes in dietary and other health behaviours in US male health professionals. J Epidemiol Community Health. 2005;59(1):56-62.
17. King AC, Kiernan M, Ahn DK, Wilcox S. The effects of marital transitions on changes in physical activity: results from a 10-year community study. Ann Behav Med. 1998;20(2):64-9.

18. Hull EE, Rofey DL, Robertson RJ, Nagle EF, Otto AD, Aaron DJ. Influence of marriage and parenthood on physical activity: a 2-year prospective analysis. J Phys Act Health. 2010;7(5):577-83.

19. Umberson D. Gender, marital status and the social control of health behavior. Soc Sci Med. 1992;34(8):907-17.

20. Lee S, Cho E, Grodstein F, Kawachi I, Hu FB, Colditz GA. Effects of marital transitions on changes in dietary and other health behaviours in US women. Int J Epidemiol. 2005;34(1):69-78.

21. Kutob RM, Yuan NP, Wertheim BC, Sbarra DA, Loucks EB, Nassir R, et al. Relationship between marital transitions, health behaviors, and health indicators of postmenopausal women: results from the Women's Health Initiative. J Women's Health (Larchmt). 2017:26(4):313-20.

22. Ortega FB, Brown WJ, Lee DC, Baruth M, Sui X, Blair SN. In fitness and health? A prospective study of changes in marital status and fitness in men and women. Am J Epidemiol. 2011;173(3):337-44.

23. Gall SL, Jose K, Smith K, Dwyer T, Venn A. The childhood determinants of adult health study: a profile of a cohort study to examine the childhood influences on adult cardiovascular health. Australasian Epidemiologist. 2009;16(1):35-9.

24. Venn AJ, Thomson RJ, Schmidt MD, Cleland VJ, Curry BA, Gennat HC, et al. Overweight and obesity from childhood to adulthood: a follow-up of participants in the 1985 Australian schools health and fitness survey. Med J Aust. 2007;186(9):458-60.

25. Craig CL, Marshall AL, Sjostrom M, Bauman AE, Booth ML, Ainsworth BE, et al. International physical activity questionnaire: 12-country reliability and validity. Med Sci Sports Exerc. 2003;35(8):1381-95.

26. Cleland VJ, Schmidt MD, Dwyer T, Venn AJ. Television viewing and abdominal obesity in young adults: is the association mediated by food and beverage consumption during viewing time or reduced leisure-time physical activity? Am J Clin Nutr. 2008:ed2008:1148-55.

27. Wilson JE, Blizzard L, Gall SL, Magnussen CG, Oddy WH, Dwyer T, et al. An ageand sex-specific dietary guidelines index is a valid measure of diet quality in an Australian cohort during youth and adulthood. Nutr Res. 2019;65:43-53.

28. Seaman SR, White IR, Copas AJ, Li L. Combining multiple imputation and inverse-probability weighting. Biometrics. 2012;68(1):129-37.

29. Paul SL, Blizzard L, Patton GC, Dwyer T, Venn A. Parental smoking and smoking experimentation in childhood increase the risk of being a smoker 20 years later: the childhood determinants of adult health study. Addiction. 2008;103(5):846-53.

30. 2011 Census of Population and Housing, Basic Community Profile: Social Marital Status by Age by Sex [database on the Internet]. ABS. 2013. Available from: https://quickstats.censusdata.abs.gov.au/census_services/getproduct/census/2 011/communityprofile/0?opendocument\&navpos=230. Accessed 30 Mar 2020.

31. 2011 Census of Population and Housing, Basic Community Profile: Occupation by Age by Sex [database on the Internet]. ABS. 2013. Available from: https://www.abs.gov.au/AUSSTATS/abs@.nsf/Lookup/4364.0.55.004 Main+Features12011-12?OpenDocument. Accessed 30 Mar 2020.

32. Australian Health Survey: Updated Results, 2011-2012: Body mass index by age and sex - Australia, states and territories [database on the internet]. ABS. 2013. Available from: https:/www.abs.gov.au/AUSSTATS/abs@.nsf/DetailsPage/4364. 0.55.0032011-2012?.0penDocument. Accessed: 30 March 2020.

33. 2011 Census of Population and Housing, Basic Community Profile: Number of Children Ever Born by Age of Parent [database on the Internet]. ABS. 2013. Available from: https://www.abs.gov.au/AUSSTATS/abs@.nsf/DetailsPage/4364. 0.55.0032011-2012? OpenDocument. Accessed 30 Mar 2020

34. Amorim AR, Rossner S, Neovius M, Lourenco PM, Linne Y. Does excess pregnancy weight gain constitute a major risk for increasing long-term BMI? Obesity (Silver Spring). 2007;15(5):1278-86.

35. Lippa RA. The preferred traits of mates in a cross-national study of heterosexual and homosexual men and women: an examination of biological and cultural influences. Arch Sex Behav. 2007;36(2):193-208

36. Wilson SE. Marriage, gender and obesity in later life. Econ Hum Biol. 2012; 10(4):431-53.

37. Schmitz K, French SA, Jeffery RW. Correlates of changes in leisure time physical activity over 2 years: the healthy worker project. Prev Med. 1997; 26(4):570-9.

38. Wilcox S, King AC. The effects of life events and interpersonal loss on exercise adherence in older adults. J Aging Phys Act. 2004;12(2):117-30. 
39. Rendall MS, Weden MM, Favreault MM, Waldron H. The protective effect of marriage for survival: a review and update. Demography. 2011 48(2):481-506.

40. Borodulin KM, Evenson KR, Wen F, Herring AH, Benson AM. Physical activity patterns during pregnancy. Med Sci Sports Exerc. 2008:40(11):1901-8.

41. Fathering in Australia among couple families with young children [database on the Internet]. Australian Government Department of Families, Housing, Community Services and Indigenous Affairs. 2010. Available from: https:// www.leavenetwork.org/fileadmin/user_upload/k_leavenetwork/Fathering_ Australia.pdf. Accessed: 5 April 2020.

42. Hook JL. Care in context: men's unpaid work in 20 countries, 1965-2003. Am Sociol Rev. 2006;71(4):639-60.

43. Aldous J, Mulligan GM, Bjarnason T. Fathering over time: what makes the difference? J Marriage Fam. 1998;60(4):809-20.

44. Uijtdewilligen L, Twisk JW, Singh AS, Chinapaw MJ, van Mechelen W, Brown WJ. Biological, socio-demographic, work and lifestyle determinants of sitting in young adult women: a prospective cohort study. Int J Behav Nutr Phys Act. 2014;11:7.

45. Candelaria Jl, Sallis JF, Conway TL, Saelens BE, Frank LD, Slymen DJ. Differences in physical activity among adults in households with and without children. J Phys Act Health. 2012;9(7):985-95.

46. Edvardsson K, Ivarsson A, Eurenius E, Garvare R, Nystrom ME, Small R, et al. Giving offspring a healthy start: parents' experiences of health promotion and lifestyle change during pregnancy and early parenthood. BMC Public Health. 2011;11:936.

47. Caspersen CJ, Pereira MA, Curran KM. Changes in physical activity patterns in the United States, by sex and cross-sectional age. Med Sci Sports Exerc. 2000;32(9):1601-9.

48. Fortier MD, Katzmarzyk PT, Malina RM, Bouchard C. Seven-year stability of physical activity and musculoskeletal fitness in the Canadian population. Med Sci Sports Exerc. 2001;33(11):1905-11

49. Troiano RP, Berrigan D, Dodd KW, Masse LC, Tilert T, McDowell M. Physical activity in the United States measured by accelerometer. Med Sci Sports Exerc. 2008;40(1):181-8.

50. Chau JY, Merom D, Grunseit A, Rissel C, Bauman AE, van der Ploeg HP. Temporal trends in non-occupational sedentary behaviours from Australian time use surveys 1992, 1997 and 2006. Int J Behav Nutr Phys Act. 2012;9:76.

51. Werneck AO, Cyrino ES, Collings PJ, Ronque ERV, Szwarcwald CL, Sardinha LB, et al. TV viewing in 60,202 adults from the National Brazilian Health Survey: prevalence, correlates, and associations with chronic diseases. J Phys Act Health. 2018;15(7):510-5.

52. Clark BK, Sugiyama T, Healy GN, Salmon J, Dunstan DW, Shaw JE, et al. Sociodemographic correlates of prolonged television viewing time in Australian men and women: the AusDiab study. J Phys Act Health. 2010;7(5):595-601.

53. Bowman SA. Television-viewing characteristics of adults: correlations to eating practices and overweight and health status. Prev Chronic Dis. 2006;3(2):A38.

54. Field AE, Aneja P, Rosner B. The validity of self-reported weight change among adolescents and young adults. Obesity (Silver Spring). 2007;15(9):2357-64.

55. Cerin E, Cain KL, Oyeyemi AL, Owen N, Conway TL, Cochrane T, et al. Correlates of agreement between Accelerometry and self-reported physical activity. Med Sci Sports Exerc. 2016;48(6):1075-84.

56. Barnaba L, Ciarapica D, Polito A. Assessment of physical activity in a Group of Adults in Italy: comparison of two different methodologies. J Phys Act Res. 2017;2(2):117-23.

57. Prince SA, Cardilli L, Reed JL, Saunders TJ, Kite C, Douillette K, et al. A comparison of self-reported and device measured sedentary behaviour in adults: a systematic review and meta-analysis. Int J Behav Nutr Phys Act. 2020;17(1):31.

58. Australian Health Survey: Physical Activity, 2011-12 [database on the Internet]. ABS. 2013. Available from: https://www.abs.gov.au/AUSSTATS/abs@.nsf/Lookup/4364. 0.55.004Main+Features12011-12?OpenDocument. Accessed 2 Apr 2020.

59. Bauman A, Ainsworth BE, Sallis JF, Hagstromer M, Craig CL, Bull FC, et al. The descriptive epidemiology of sitting. A 20-country comparison using the international physical activity questionnaire (IPAQ). Am J Prev Med. 2011;41(2):228-35.

60. Census of Population and Housing: Census Dictionary 2011, Glossary, marital status [database on the internet]. ABS. 2011. Available from: https:// www.abs.gov.au/ausstats/abs@.nsf/Lookup/2901.0Chapter40402011. Accessed: 30 March 2020.

61. Kreider RM, Simmons T. Marital Status: 2000, Census 2000 brief. Washinton, DC: US Census Bureau; 2000.

62. Reimondos A, Evans A, Gray E. Living-apart-together (LAT) relationships in Australia. Fam Matters. 2011;87:43-55.

\section{Publisher's Note}

Springer Nature remains neutral with regard to jurisdictional claims in published maps and institutional affiliations.
Ready to submit your research? Choose BMC and benefit from:

- fast, convenient online submission

- thorough peer review by experienced researchers in your field

- rapid publication on acceptance

- support for research data, including large and complex data types

- gold Open Access which fosters wider collaboration and increased citations

- maximum visibility for your research: over $100 \mathrm{M}$ website views per year

At $\mathrm{BMC}$, research is always in progress.

Learn more biomedcentral.com/submissions 


\section{University Library}

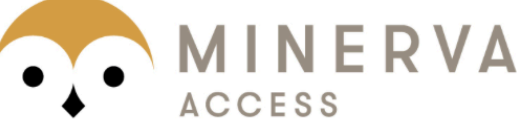

A gateway to Melbourne's research publications

Minerva Access is the Institutional Repository of The University of Melbourne

Author/s:

Tian, J;Smith, KJ;Cleland, V;Gall, S;Dwyer, T;Venn, AJ

Title:

Partnering and parenting transitions in Australian men and women: associations with changes in weight, domain-specific physical activity and sedentary behaviours.

Date:

2020-07-08

\section{Citation:}

Tian, J., Smith, K. J., Cleland, V., Gall, S., Dwyer, T. \& Venn, A. J. (2020). Partnering and parenting transitions in Australian men and women: associations with changes in weight, domain-specific physical activity and sedentary behaviours.. Int J Behav Nutr Phys Act, 17 (1), pp.87-. https://doi.org/10.1186/s12966-020-00989-6.

Persistent Link:

http://hdl.handle.net/11343/244984

License:

CC BY 